Мурашов Сергей Борисович

доктор социологических наук, доцент, ректор Северо-Западного института повышения квалификации ФНС России

\section{СОЦИАЛЬНЫЕ ТЕХНОЛОГИИ КАК СРЕДСТВО МОДЕРНИЗАЦИИ СИСТЕМЫ УПРАВЛЕНИЯ}

\section{Аннотация:}

Автором статьи обоснован ряд положений, позволяющих концептуализировать социальные технологии в качестве средства модернизации системы социального управления, ее качественного улучшения для достигаемых социальных результатов и обеспечения социальной устойчивости. Рассмотрена система управления организации как объект данного исследования. Определены оптимизационно-конструктивный потенциал социальных технологий, приоритетные направления его использования в решении задач по развитию организационных систем управления. С учетом оптимизационноконструктивных свойств исследуемых технологий охарактеризованы соответствующие принципиальные направления их применения в целях модернизации систем управления в организациях. В заключение обоснован логический вывод о том, что потенциал социальных технологий в изучаемом аспекте cостоит в достижении более высокого уровня качества социального взаимодействия в системе управления и ее внешних взаимоотношениях, а также в получении положительных социальных результатов управления за счет создания новой, оптимизированной социоуправленческой модели. Положительные результаты предполагают прежде всего улучшение или расширение определенных социальных благ для трудового коллектива.

\section{Ключевые слова:}

организации, социология управления организаци ями, социальные технологии в управлении, модернизация системы управления, социальные результаты управления, социальная устойчивость системы управления, концептуальное моделирование систем управления, социальное взаимодействие.

\section{Murashov Sergey Borisovich}

D.Phil. in Social Science, Associate Professor, Rector, North-West Federal Tax Service Training Institute

\section{SOCIAL TECHNOLOGIES AS THE MEANS OF MANAGEMENT SYSTEM IMPROVEMENT}

The author substantiates the fact that social technologies can be considered as a way to improve social management system, achieve better social effects, and provide social sustainability. The research focuses on the management system of the organization. The paper defines the enhancement and constructive potential of social technologies, their priorities for addressing development concerns of the company's management system. Based on the enhancement and constructive properties of the aforementioned technologies, the study describes the major scope of their application aimed at improving management systems in organizations. In conclusion, the researcher proves that social technologies are to achieve strong social cooperation in the management system and its external relations and obtain positive social managerial effects through the construction of a new enhanced social management model. Positive results primarily imply the improvement or expansion of certain social benefits to the work community.

Keywords:

organizations, sociology of company's management, social technologies in management, management system improvement, social managerial effects, management system social resilience, conceptual construction of management systems, social interaction.

На основании анализа изученной специальной литературы о социальных технологиях в управлении можно, на наш взгляд, утверждать, что рассматриваемая в настоящей статье тема специалистами исследована недостаточно. Сегодня по-прежнему актуальна проблема концептуализации и методологии социальных технологий в управленческой деятельности. В ряде авторитетных источников отмечено, что концептуализация социальных технологий в управлении пока не нашла своего теоретического оформления [1].

При рассмотрении трудов зарубежных исследователей в данной области, написанных в основном на английском языке, необходимо иметь в виду следующее. Смысл понятия «социальные технологии» (social technologies), фригурирующего в соответствующей англоязычной литературе, не тождественен смыслу, который вкладывают в него российские социологи. В иностранных исследованиях, выполненных под рубрикой «social technologies», акцент сделан преимущественно на проблематике использования информационно-коммуникационных технологий (а более широко - hightech) в социальном менеджменте или в бизнесе [2]. Российские социологи трактуют понятие «социальные технологии» гораздо шире, с акцентом на социальных взаимодействиях, мотивах их структурирования и оптимизации в управлении, а не на технических или информационно-коммуникационных инструментах обеспечения этих взаимодействий. Значительное внимание уделяется социальным результатам, достигаемым с помощью социальной технологизации процессов управления. 
Достаточно детальный обзор нескольких видов толкования изучаемого нами понятия можно найти в фундаментальной работе Б.Н. Герасимова и В.Г. Чумака [3, с. 93-105]. Другими авторами в одном из определений выражена мысль о назначении социальных технологий в управлении, которое состоит в том, чтобы оптимизировать управленческий процесс за счет выявления и использования скрытого потенциала системы социального управления для получения заданных социальных результатов с наименьшими издержками [4, с. 152].

В настоящей статье проблема исследована в ином аспекте с позиции назначения социальных технологий в управлении. В частности, предлагается теоретическая концептуализация социальных технологий как средства использования потенциала развития при решении задач модернизации систем управления в организациях.

Как свидетельствуют современные научные исследования, управленческие подходы и технологии, реализуемые в настоящее время в крупных организациях (особенно территориально-распределенных), провоцируют ошибки в принятии решений, обусловливают малую эфффективность систем управления в целом и ограничивают возможности их развития [5]. Наиболее критична такая распространенная управленческая проблема, как выработка определенных моделей управленческого поведения, что приводит к их неизменному и постоянному использованию на фоне стремления к искоренению любых других моделей. Ситуация обостряется ввиду усложнения и увеличения объемов документооборота, внутрисистемных и внешних социальных взаимодействий, затруднений в координации всех участников. Следствием этого является дезинтеграция организационных структур и десрормализация социально-управленческих процессов, затрудняющая их контролируемость со стороны руководства. Все эти обстоятельства, несомненно, актуализируют необходимость изыскания ресурсов социоуправленческой оптимизации и модернизационного развития, выработки новых, в том числе и социологически обоснованных, управленческих подходов на базе междисциплинарной интеграции в управлении [6]. В этом плане может быть использован системнооптимизационный и конструктивный потенциал социальных технологий.

Предлагаем для более полного, предметного понимания проблемы собственный авторский подход к содержанию и толкованию понятия «социальные технологии» в контексте рассматриваемой нами системы управления. Социальные технологии в системе управления представляют собой социоуправленческие механизмы регуляции взаимоотношений между участниками совместной управленческой деятельности. Данные механизмы оптимизируют операционную функциональность и стабильность организации (ее процессов), а также создают потенциал модернизации системы управления и качественного улучшения социальных результатов принимаемых управленческих решений. При этом под социоуправленческим механизмом мы подразумеваем алгоритм социальных действий, структурированных субъектом управления как поэтапный и целерациональный путь решения взаимосвязанных управленческих задач.

Рассмотрим более подробно авторское видение некоторых потенциальных возможностей модернизации систем социального управления за счет социальных технологий. Отправной точкой нашего исследования послужили ключевые идеи, отраженные в содержательных фундаментальных работах. В них прямо или косвенно освещены важные социолого-управленческие вопросы, связанные с модернизационным развитием систем управления в деловых организациях, в том числе с их концептуальным моделированием [7].

Итак, комплексная работа по улучшению системы управления представляет собой институциональную оптимизацию ролей, функций и способов социального взаимодействия. Суть данного тезиса заключается в улучшении качественных и количественных характеристик институтов управления на основе специально разработанных критериев, служащих мерилом эффрективности этих институтов. Соответствующий аспект связан также с потребностью обеспечить документирование (в виде внутренних нормативных и методических документов) всех институциональных изменений для разных структурных подразделений, рабочих групп и сотрудников.

Важно помнить о том, что влияние неформальных институтов на качество системы управления весьма значительно. Существуют организации, где деформализация приобретает такие масштабы, что неформальные институты вытесняют собой формальные. Для руководителя, который стремится оптимизировать управляемый трудовой коллектив, деформализующие тенденции должны являться объектом анализа и ограничения, так как они выступают фракторами риска организационной дезинтеграции и ослабления управляемости.

Преимущества ролевой и функциональной оптимизации на основе социальной технологии состоят в следующем. Если новая роль вводится как элемент социальной технологии, ее задачи более четко определены и действия алгоритмизированы, как и стадии, на которых осуществляется определенный способ социального взаимодействия. Причем функциональная ответственность более мотивирована, ввиду того что ненадлежащее выполнение влияет на всеобщий процесс, составляющий технологию. Если же вводится новая роль вне связи с социальной технологией, то вероятен риск того, что ее функции окажутся фиктивными, как и социальные взаимодействия с ее участием. 
В практике управления организациями существуют примеры квазиролей, которые, не будучи встроенными в организационно-деловые процессы как неотъемлемые элементы, малоэффективны. В числе потенциально неэффективных ролей кризисный менеджер, риск-менеджер, менеджер по развитию, креативный менеджер, директор по управлению знаниями. Приведенные в качестве примеров роли, конечно, нельзя считать бесполезными по определению. Проблема может возникнуть лишь в том случае, когда в организации система управления находится не на должном уровне с точки зрения критериев ее эффективной работы на основе процессного подхода (система кризисного управления, система управления рисками или система управления знаниями и т. д.). Иными словами, неоптимизированность организационно-деловых процессов обусловливает неэффективность действий их участников.

Наиболее гибкими считаются, как правило, при изменении ролей, функций и способов социального взаимодействия организации непроизводственной сферы (сферы услуг). Например, радикально меняются социальные технологии в образовательных учреждениях, как во внутренних взаимоотношениях, так и во внешних, т. е. с клиентами, которым предоставляются образовательные услуги. Происходит изменение роли и функций преподавателя: он становится в большей степени методологом и консультантом, чем наставником, как было ранее. Контрольно-оценочная функция преподавателя становится доминирующей. Изменение типов социального взаимодействия проявляется в сокращении межличностных коммуникаций при увеличении доли дистанционных взаимодействий. Дистанцирование в преподавании имеет свои положительные стороны: исчезает субъективный фрактор и коммуникативные конфликтогенные риски, отпадает необходимость в физическом перемещении, что экономит время и трудозатраты преподавателя. Такая форма преподавания, как вебинары, представляется нам достаточно перспективной технологией взаимодействия преподавателя со студентами, и эта фоорма, по-видимому, вскоре способна вытеснить традиционную аудиторную работу. В целом, принимая во внимание социальный эффект дистанционных технологий, несомненно, обучение становится ффизически и психологически более комфортным, менее трудозатратным для его участников.

Формализация социального взаимодействия, по нашему мнению, является ключевым понятием, связанным с социальными технологиями в системе управления. Если рассматривать этот вопрос шире, то становится очевидно, что общая проблема фрормализуемости систем социального управления чрезвычайно актуализируется в настоящее время. Между тем в социологической литературе немного исследований, посвященных данной проблеме. В одной из монографий тема формализации социального управления освещена достаточно детально [8]. В частности, А.Б. Юсов подчеркивает критичность вопроса с точки зрения обеспечения эффективного развития социальных систем в сложных современных условиях. Новые механизмы социального управления, по мнению автора, должны быть основаны на «формализованных методиках оценки состояния и формализованных методах проверки результатов управления» [9, с. 57]. Дополним, что для применения соответствующих методов нельзя не учитывать возможности разработки и использования самых разнообразных, в том числе качественных, критериев.

Системы управления в организациях, представляющие собой разновидности социального управления, можно квалифицировать как слабоформализуемые образования, поскольку они в большей степени подвержены влиянию разнообразных фракторов дестабилизации и рисков, обусловленных, в свою очередь, человеческим фрактором. Как указано в монографии [10, с. 59], в системах социального управления все факторы взаимообусловлены, а значит, для каждой пары фракторов изменение одного рано или поздно влечет за собой изменение другого. Таким образом, и в системах управления организаций независимых факторов практически не бывает, и именно тех, что зависели бы лишь от времени. Это усложняет прогнозирование и увеличивает управленческие риски, т. е. риски принятия неверных решений, а также их ненадлежащего исполнения. Очевидна критичность, острота проблемы формализации организационно-управленческих процессов, так как именно при ее успешном решении достигаются социальная устойчивость и регулярность социального взаимодействия, качество и эффективность системы управления организации в целом.

Поскольку «управляемый социум» (трудовой коллектив) имеет тенденцию к деформализации отношений и разного рода девиациям, особенно если управляющая система долго придерживается однажды установленных, неизменных принципов и методов руководства, для восстановления и закрепления должного уровня формализации системы управления требуется оптимизация существующих или создание новых социальных технологий. В общеуправленческом смысле формализация означает, что для системных управленческих процессов четко определяются и документируются ключевые характеристики, обеспечивающие их регулярность и устойчивость.

Эти характеристики должны быть либо оценены количественно с помощью доступных методов измерения (что более характерно для технических систем, но частично может быть приме- 
нено и в социальных системах), либо они (характеристики) должны иметь четкое текстовое описание, не допускающее толкований (что более характерно для систем социального управления). Документированную информацию о формализованных ситуациях социально-управленческого взаимодействия доводят до сведения должностных лиц в виде инструкций, регламентов и методических руководств.

Можно выделить следующие основные социоуправленческие характеристики, позволяющие формализовать систему управления организации: 1) структурирование социальных целей и задач управления; 2) условия инициации каждого процесса управления; 3) социальная технология реализации процесса управления; 4) четкая регламентация действий руководителя процесса и ответственных лиц на каждой стадии; 5) порядок взаимодействия лиц в системе принятия решений; 6) процедура доведения решений до исполнителей; 7) порядок исполнения решений; 8) способы отчетности исполнителей; 9) санкции за ненадлежащее исполнение решений; 10) критерии подбора, расстановки и ротации кадров; 11) регламентация по времени; 12) критерии эффективности лиц, принимающих решения, и исполнителей.

Один из важных компонентов формализации организационной системы управления - процедуры оценки эффективности управленческой деятельности. Оценивать можно эффективность всей системы управления, эффективность работников или функциональных групп совместной работы. Если выстроить процедуру оценки как социальную технологию, то мы получим более формализованный аспект управленческой деятельности, где определены этапы оценки, состав участников и их ролевые функции, опирающиеся на четкие методические и регламентные описания. В целом формализация процессов и взаимоотношений в системе управления, если она осуществляется на базе социальных технологий, способствует повышению обоснованности и качества принятия управленческих решений, более точному и корректному выполнению процессов управления, их надежности и улучшению.

Рассматривая вопрос о социоуправленческой интеграции, нельзя не отметить, что для большинства систем управления в организациях характерна тенденция к усилению дифференциации ресурсов и процессов, что выражается в дезинтеграции организационных структур и нарушении координации в социальном взаимодействии. Следствием этого является ослабление транспарентности и контролируемости организационных процессов руководством, а также нарастание издержек в системе управления [11]. В итоге руководству необходимо своевременно оптимизировать интеграционные механизмы в системе управления. Среди них - введение специальных административных процедур; управленчески обоснованная ротация ключевых кадровых позиций; консолидация организационной культуры; создание единой базы организационных знаний; формирование так называемых межфункциональных групп для консолидации кадровых ресурсов по управлению сложными аспектами деятельности организации; введение специальных координирующих позиций, а также рабочих групп, реализующих интегрирующую и координирующую функцию.

Одно из системных интеграционных решений - создание обеспечивающих социоуправленческих механизмов, которые играют роль метатехнологий и поддерживают какую-либо основную управленческую технологию. Для определения обеспечивающих или обслуживающих механизмов целесообразно, как нам кажется, применять понятие «социоуправленческие интеграторы». Последние могут быть узкоспециализированными или комплексными, иметь разнообразные социальнотехнологические реализации, в зависимости от специфики задач той системы или подсистемы управления, которую они «обслуживают». Такого рода технологии находят отражение в одной из известных фрорм комплексного управления - контроллинге персонала (кадровом контроллинге) [12].

Комплексный характер контроллинга персонала позволяет реализовать несколько социальных технологий, создающих возможности для повышения эффективности системы управления персоналом. Социальная технологизация процессов контроллинга способна обеспечить устойчивую регуляцию выполнения сложных и даже трудновыполнимых задач, в частности: а) анализ взаимосвязей между существенными характеристиками работников, планами их размещения и социальными результатами трудовой деятельности; б) исследование проблем социальной и экономической эффективности процессов и методов управления персоналом, а также проблем социальных рисков; в) координация кадрового планирования с деятельностью других функциональных направлений в организации.

В заключение можно сделать вывод о том, что потенциал социальных технологий в целях модернизации систем управления в организациях состоит в достижении более высокого уровня качества социального взаимодействия в процессах управления и во внешних взаимоотношениях организации, а также положительных социальных результатов управления за счет внедрения новой, более формализованной и интегрированной социоуправленческой модели.

Положительные социальные результаты предполагают улучшение или расширение определенных социальных благ для трудового коллектива. Среди них - улучшение внутрисистемной 
социальной среды и условий труда; гармонизация интересов различных групп и индивидов в системе управления; снижение конфликтогенности организации; профессиональное и креативное развитие; создание условий для самореализации, повышения трудового статуса; введение новых способов стимулирования работников; стабильность и рост заработной платы; наличие различных способов поддержки работников в критических ситуациях; повышение гарантий безопасности труда; дополнительное страхование сотрудников и т. п. Социальные блага, создаваемые реализаторами проекта развития системы управления, необходимы для восстановления человеческих ресурсов и формирования таких качеств, как работоспособность, мотивированность, креативность и неконфликтность.

\section{Ссылки:}

1. Бурмыкина И.В. Методологические основания теории социальных технологий современности // Вестник Московского университета. Сер. 18. Социология и политология. 2013. № 4. С. 151-161; Герасимов Б.Н., Чумак В.Г. Социальные технологии в управлении : монография. Самара, 2014. 396 с. ; Касавин И.Т. Социальные технологии. Теоретические концептуализации и примеры // Общественные науки и современность. 2012. № 6. С. 100-111.

2. Bughin J., Byers A.H., Chui M. How Social Technologies are Extending the Organizations [Электронный ресурс] // McKinsey \& Company. 2011. November. URL: https://www.mckinsey.com/industries/high-tech/our-insights/how-social-technologies-are-extending-the-organization (дата обращения: 03.02.2019) ; Derksen M., Vikkelsø S., Beaulieu A. Social Technologies: Cross-disciplinary Reflections on Technologies in and from the Social Sciences // Theory \& Psychology. 2012. Vol. 22, no. 2. P. 139-147. https://doi.org/10.1177/0959354311427593.

3. Герасимов Б.Н., Чумак В.Г. Указ. соч. С. 93-105.

4. Бурмыкина И.В. Указ. соч. С. 152.

5. Калачев И.В. Социальные технологии в управлении современной организацией : дис. ... канд. социол. наук. Тюмень, 2004. 173 с. ; Корезин А.С. Менеджмент и контроллинг безопасности предприятия : монография. СПб., 2011. 242 с. ; Его же. Методология развития системы экономической безопасности предприятия на базе корпоративных механизмов управления рисками : автореф. дис. ... д-ра экон. наук. СПб., 2009. 39 с.

6. Корезин А.С.: 1) Менеджмент и контроллинг ... ; 2) Методология развития системы ...

7. Герасимов Б.Н., Чумак В.Г. Указ. соч. ; Калачев И.В. Указ. соч. ; Корезин А.С. Методология развития системы ... ; Корезин А.С., Мурашов С.Б. Инновации в системе социального управления (социологическая теория управленческих инноваций) : учеб. пособие / под общ. ред. С.Б. Мурашова. СПб., 2017. 111 с.

8. Юсов А.Б. Теория социального управления (новый взгляд на старые проблемы). Саарбрюккен, 2012. 92 с.

9. Там же. С. 57.

10. Там же. С. 59

11. Корезин А.С.: 1) Менеджмент и контроллинг ... ; 2) Методология развития системы ...

12. Корезин А.С. Менеджмент и контроллинг ... ; Корезин А.С., Мурашов С.Б. Указ. соч. ; Маликова С.Г. Контроллинг персонала // Служба кадров и персонал. 2004. № 1. С. 88-91.

\section{References:}

Bughin, J, Byers, AH \& Chui, M 2011, 'How Social Technologies are Extending the Organizations', McKinsey \& Company, November, viewed 4 February 2019, <https://www.mckinsey.com/industries/high-tech/our-insights/how-social-technologies-areextending-the-organization>.

Burmykina, IV 2013, 'Methodological Foundations of the Theory of Social Technologies of Modernity', Vestnik Moskovskogo universiteta. Ser. 18. Sotsiologiya i politologiya, no. 4, pp. 151-161, (in Russian).

Derksen, M, Vikkelsø, S \& Beaulieu, A 2012, 'Social-Disciplinary Reflections and Social Sciences', Theory \& Psychology, vol. 22, no. 2, pp. 139-147, https://doi.org/10.1177/0959354311427593.

Gerasimov, BN \& Chumak, VG 2014, Social Technologies in Management: a monograph, Samara, 396 p., (in Russian).

Kalachev, IV 2004, Social Technologies in the Management of Modern Organization, PhD thesis, Tyumen, 173 p., (in Russian).

Kasavin, IT 2012, 'Social Technology. Theoretical Conceptualizations and Examples', Obshchestvennyye nauki i sovremennost', no. 6, pp. 100-111, (in Russian).

Korezin, AS 2009, Methodology of Development of the System of Economic Security of an Enterprise on the Basis of Corporate Risk Management Mechanisms, D.Phil. thesis abstract, St. Petersburg, 39 p., (in Russian).

Korezin, AS 2011, Management and Controlling Enterprise Security: a monograph, St. Petersburg, 242 p., (in Russian).

Korezin, AS \& Murashov, SB 2017, Innovations in the System of Social Management (Sociological Theory of Managerial Innovations): textbook, St. Petersburg, 111 p., (in Russian).

Malikova, SG 2004, 'Personnel Controlling', Sluzhba kadrov i personal, no. 1, pp. 88-91, (in Russian).

Yusov, AB 2012, The Theory of Social Management (a New Look at Old Problems), Saarbrucken, 92 p., (in Russian). 